\title{
Training of optical engineers and physicists in Chernovtsy University
}

Oleg Angelsky, G. Kurek, Bohdan Nitsovich

Oleg V. Angelsky, G. K. Kurek, Bohdan M. Nitsovich, "Training of optical engineers and physicists in Chernovtsy University," Proc. SPIE 1603, Education in Optics, (1 March 1992); doi: 10.1117/12.57892

SPIE. Event: Education in Optics, 1991, Leningrad, Russian Federation 
Training of optical engineers and physicists in Chernovtsy University

$$
\text { O.V.Angelsky, G.K.Kurek, B.M.Nitsovich }
$$

Chernovtsy University, 274012 Chernovtsy, Ukraine, USSR.

The first group of students to be trained in optics was admitted to Chernovtsy University in 1962. At thattime the Optical Division was part of the Physical Faculty and was represented by a single specializing department. The research interests of the Department members formed under the influence of leading specialists from all over the country, which gave lectures to the teachers and students of the Optical Division. The lectures were given by Professors A.A.Shishlovsky, G.V.Rozenberg, R.Sapozhnikov, V.M.Broude, V.M.Fine. The teachers and students were able to take part in the seminars held by Professors K.S..Shifrin, I.V.Obreimov, Yu.N.Denisyuk, A.P.Ivanov. Thanks to the broad scientific contacts, the fields of research have been outlined which included both traditional fields such as optics of scattering objects, the theory of propagation and the theory of radiation transport, spectroscopy of scattering media, and new fields such as optical field coherence, laser theory and technology, holography, etc.

Giving due consideration to fundamental aspects of optical education from ray optics to atomic and molecular spectroscopy, we introduced in due time such new courses, as "Lasers" (1965), "Optical Image Patterns and Holography" (1966), etc.

In 1980 the Optical Department was transformed into the Faculty of Optical Engineering which included two newly organized departments, i.e. the Department of Correlation Optics and the Department of Optics and Spectroscopy. The total number of students admitted was 50 . Later on (in 1987) the Department of General Physics was added to the Faculty. The total number of students admitted in 1991 was 75.

The training of optical engineers and physicists is carried out in the following specializations: "Optical Information Devices and Systems", "Optoelectronic Devices and Systems", "Optical and Laser Devices in Medicine", and "Optical and Physical Devices in Biology and Medicine". The last two specialities are new, and are intended to train specialists for medical research institutions and hospitals.

The Faculty currently has the staff of 27, among them 4 professors (Doctors of Science) and 17 associate professors (Candidates of Science). They conduct such courses as "Statistical Optics", "Wave Optics", "Optics of Scattering Media", "Lasers and Quantum Amplifiers", "Holography", "Photometry", etc.

The Faculty does about 1 million roubles' worth of research work a year on contracts with industrial enterprises. 
During the last 3 years three all-union schools and conferences and an international conference "Lamiladis-91" have been held in Chernovtsy with the participation of the Faculty. Chernovtsy University joined the Soviet Union Chapter of SPIE in 1991, and is one of the founders of the Ukrainian Optical Society. The Faculty seeks to expand scientific and educational contacts and plans to conduct a series of events in Chernovtsy using the available facilities. 